\title{
Practically prepared? Pre-intern student views following an education package: a response
}

\section{Naeem Dowlut \\ School of Medicine, Barts and The London School of Medicine, London, UK}

This article was published in the following Dove Press journal:

Advances in Medical Education and Practice

5 April 2017

Number of times this article has been viewed

\section{Dear editor}

I read with interest the paper authored by McKenzie and Mellis regarding the delivery and student feedback of an educational package, as part of the pre-internship module, designed to improve clinical skills, including procedural skills, of final-year medical students. ${ }^{1}$ The educational package was delivered prior to students commencing their clinical attachment component of the module and consisted of didactic-, group-, and case-based teaching sessions. Given the significant improvements in the self-reported confidence of students following the pre-internship module, and from my own experience, I agree with the authors that an intensive educational program is highly valuable at improving the skills and confidence of students prior to commencing clinical practice.

In the UK, the General Medical Council requires UK medical schools to integrate "student assistantships" into the final year of medical school, before the medical student transitions into a practicing first-year postgraduate doctor ("Foundation Year 1" or "F1"). ${ }^{2}$ Depending on the medical school, the student assistantship is of varying length and is intended to closely integrate students into the health care team so that they may obtain more practical experience of a newly qualified doctor's role. During this assistantship, students should perform a diverse set of supervised practical procedures on patients, ranging from measurement of body temperature to catheterization and skin suturing. ${ }^{2}$ It has been shown that student assistantship model does improve the student's preparedness for clinical practice.,

While it is encouraging to see the success of student assistantships, there is still potential for improvement, especially with regard to procedural competencies. It is no surprise that over the years of medical school, most students have had the opportunity to take a blood sample or insert a cannula, without the need of an assistantship. Opportunities such as these regularly present themselves on clinical placement, and most clinical staff permit students to practice these skills on suitable patients. However, despite the presence of student assistantships, the results of this study demonstrate that a sizeable proportion of medical students had still not had the opportunity to sufficiently practice several important procedural skills, including the insertion of a nasogastric tube, the performance of an electrocardiogram on a patient or a peer, and the insertion of a urinary catheter. Furthermore, some students may have only practiced a procedure on one patient and, in the case of urinary catheters, students may have only practiced on one gender alone. As such, the fact remains
Correspondence: Naeem Dowlut

Biomedical Engineering and Clinical Materials, Barts and The London School of Medicine, 4 Newark Street, London EI 2AT, UK

Email m.dowlut@smdI2.qmul.ac.uk 
that not all students will have had the opportunity to sufficiently practice all fundamental procedural skills before transitioning into a practicing doctor, even with the presence of student assistantships.

Rather than advocating for lengthier assistantships or placements, I believe that small efforts can enhance overall student exposure, and thus confidence, in procedural skills. This includes encouragement of clinical staff to support and facilitate regular opportunities for students to practice procedural skills from the very start of clinical placements, and where students have felt that they have had insufficient experience of a particular procedure, medical schools should offer reasonable alternatives, such as access to models for practice on under clinical guidance.

\section{Disclosure}

The author reports no conflicts of interest in this communication.

\section{References}

1. McKenzie S, Mellis C. Practically prepared? Pre-intern student views following an education package. Adv Med Educ Pract. 2017;8:111-120.

2. GMC. Clinical Placements for Medical Students. Available from: http:// www.gmc-uk.org/Clinical_placements_for_medical_students__guidance_under_review_0815.pdf_56437824.pdf. Accessed February 1, 2017.

3. Braniff C, Spence RA, Stevenson M, Mairhead B, Watson P. Assistantship improves medical students' perception of their preparedness for starting work. Med Teach. 2016;38(1):51-58.

4. Jones OM, Okeke C, Bullock A, Wells SE, Monrouxe LV. 'He's going to be a doctor in August': a narrative interview study of medical students' and their educators' experiences of aligned and misaligned assistantships. BMJ Open. 2016;6(6):e011817. 


\section{Authors' reply \\ Susan McKenzie \\ Craig Mellis \\ Central Clinical School, Sydney Medical School, The University of Sydney, Camperdown, NSW, Australia}

Correspondence: Susan McKenzie

Central Clinical School, Sydney Medical School, The University of

Sydney, Building 63, Level 4, Royal Prince Alfred Hospital,

Missenden Road, Camperdown, NSW 2050, Australia

Tel +6I 295156548

Email susan.mckenzie@sydney.edu.au

\section{Dear editor}

Thank you for providing the opportunity to respond to the letter by Mr Dowlut.

We wish to thank Mr Dowlut for his thoughtful feedback on our recent manuscript. ${ }^{1}$ It is deeply encouraging that the importance of educational programs of this nature are recognized.

We strongly agree with the benefits of "shadowing" or "assistantship" prior to medical graduates transitioning into pre-vocational training. More recently, “"“shadowing” has been made mandatory in Australian hospitals to allow new interns to "shadow" the outgoing intern in the week prior to commencing clinical duties. Further education is also made available at intern orientation, and whilst beneficial, these sessions are not yet standardized and do vary from region to region.

Despite the benefits of "shadowing", or "student assistantships", we agree the variations in opportunities to observe and perform core procedural skills remain. Hence, the reported value of intensive educational programs such as ours in improving the skills and confidence of students prior to commencing pre-internships.

\section{Disclosure}

The authors report no conflicts of interest in this communication.

\section{Reference}

1. McKenzie S, Mellis C. Practically prepared? Pre-intern student views following an education package. Adv Med Educ Pract. 2017;8:111-120.

Dove Medical Press encourages responsible, free and frank academic debate. The content of the Advances in Medical Education and Practice 'letters to the editor' section does not necessarily represent the views of Dove Medical Press, its officers, agents, employees, related entities or the Advances in Medical Education and Practice editors. While all reasonable steps have been taken to confirm the content of each letter, Dove Medical Press accepts no liability in respect of the content of any letter, nor is it responsible for the content and accuracy of any letter to the editor.

\section{Publish your work in this journal}

Advances in Medical Education and Practice is an international, peerreviewed, open access journal that aims to present and publish research on Medical Education covering medical, dental, nursing and allied health care professional education. The journal covers undergraduate education, postgraduate training and continuing medical education including emerging trends and innovative models linking education, research, and health care services. The manuscript management system is completely online and includes a very quick and fair peer-review system. Visit http://www.dovepress.com/testimonials.php to read real quotes from published authors. 